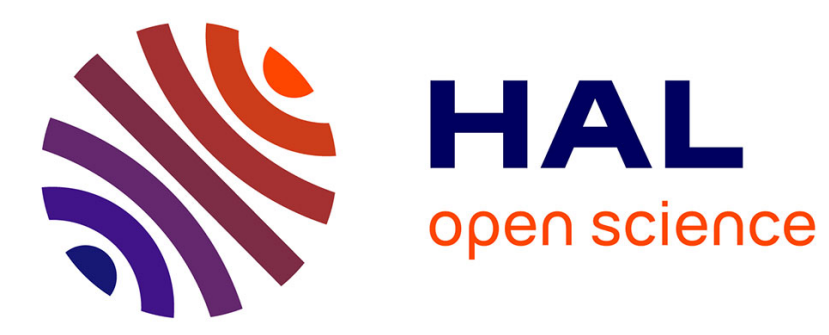

\title{
Interstitial devices for minimally invasive thermal ablation by high-intensity ultrasound.
}

\author{
Cyril Lafon, David Melodelima, Rares Salomir, Jean Yves Chapelon
}

\section{To cite this version:}

Cyril Lafon, David Melodelima, Rares Salomir, Jean Yves Chapelon. Interstitial devices for minimally invasive thermal ablation by high-intensity ultrasound.. International Journal of Hyperthermia, 2007, 23 (2), pp.153-63. inserm-00158736

\section{HAL Id: inserm-00158736 https://www.hal.inserm.fr/inserm-00158736}

Submitted on 29 Feb 2008

HAL is a multi-disciplinary open access archive for the deposit and dissemination of scientific research documents, whether they are published or not. The documents may come from teaching and research institutions in France or abroad, or from public or private research centers.
L'archive ouverte pluridisciplinaire HAL, est destinée au dépôt et à la diffusion de documents scientifiques de niveau recherche, publiés ou non, émanant des établissements d'enseignement et de recherche français ou étrangers, des laboratoires publics ou privés. 
Interstitial devices for minimally invasive thermal ablation by high intensity ultrasound

Cyril LAFON, David MELODELIMA, Rares SALOMIR, Jean Yves CHAPELON

Inserm, U556, Lyon, F-69003 France ; Université Claude Bernard Lyon 1, Lyon, F-69000

France

Corresponding author :

Cyril Lafon

INSERM U556

151 Cours Albert Thomas

69424 LYON Cedex 03

France

Pho: +33 4726819 20; Fax: +33 47268 19 31; Email: Lafon@lyon.inserm.Fr

Keywords : Review, Ultrasound, Interstitial, thermal ablation 
Interstitial devices for minimally invasive thermal ablation by high intensity ultrasound

\begin{abstract}
Interstitial ultrasound applicators have been proposed for treating deep-seated tumors that can not be reached with extracorporeal High Intensity Focused Ultrasound. In addition, interstitial ultrasound offers several advantages compared with conventional ablation technology (radiofrequency, microwaves, cryotherapy ...) in terms of penetration, speed of coagulation, ability to direct and control the thermal lesion and compatibility with image monitoring. The ultrasound source is brought as close as possible to the target in order to minimize the effects of attenuation and phase aberration along the ultrasound pathway. The present paper is a review of the interstitial applicators that were described during the last decade in the literature. It is presented in three sections. The technical aspects common to all applicators are first described. For example, most described applicators are sideview applicators which active element is water-cooled and operates at rather high frequency (above $3 \mathrm{MHz}$ ) in order to promote heating. Then the different potential techniques for monitoring treatment administered by the interstitial route are presented and illustrated through a review of imageguided interstitial thermal ablation. Three major techniques of imaging are used for guiding interstitial treatment: MRI, ultrasound and fluoroscopy. The third section will go further in detail on diverse described medical applications.
\end{abstract}




\section{Introduction}

Thermal ablation of localized tumors or pathological tissues using High Intensity Focused Ultrasound (HIFU), proposed in the $50 \mathrm{~s}^{1}$, is now a widely accepted therapeutic method. Several devices are currently marketed and can be used to treat, for example, prostate cancers $^{2,3}$, uterine fibromas ${ }^{4}$ or liver tumours ${ }^{5,6}$. When using a large extracorporeal focused transducer, the pressure gain between the surface of the transducer and its focal point increases. Following this approach, intervening tissues can be preserved, resulting in a completely non-invasive therapy. However, interstitial applicators, positioned inside tissues, were more recently proposed for targeting sites where extracorporeal HIFU are not suitable. Bones or gaseous pockets may indeed be located in the intervening tissues and deep-seated sites may be difficult to access from outside the patient. In biological tissues, the ultrasound wave is naturally attenuated and deformed on meeting structures with different geometric and acoustic properties. Attenuation or phase aberration during treatment of deep-seated sites results in a decrease in pressure gain. In this case, pressure can be increased at the surface of the transducer in the hope of supplying sufficient energy to the focal point, but this increase is to the detriment of intervening tissue whose temperature will also rise. Minimally invasive interstitial methods bring the ultrasound source into contact with the target in order to minimize the effects of attenuation and phase aberration. The original objective with these interstitial applicators was to work in the range of temperature for conventional hyperthermia and in conjunction with brachytherapy ${ }^{7}$. Now, these interstitial applicators like HIFU transducers are designed for performing thermal ablation. Furthermore, it should be kept in mind that, in contrast to extracorporeal applicators, interstitial probes impose additional design constraints with regard to size and ergonomy.

Other interstitial techniques such as radiofrequency (RF), lasers, microwaves or cryosurgery 
are clinically used. However, several advantages of ultrasound have motivated the development of interstitial and intraluminal ultrasound devices. Interstitial ultrasound applicators present four major advantages compared to those using other tissue heating methods, such as RF applicators ${ }^{8}$, lasers ${ }^{9}$ and cryosurgery ${ }^{10}$. The first is the ability to apply the thermal dose quickly, thus limiting the diffusion of heat into the tissue and increasing the depth of treatment ${ }^{11}$. Deardorff et al. ${ }^{12}$ compared an ultrasound applicator with a microwave antenna and showed the better control of thermal coagulation with the ultrasound device. The second advantage is that the ultrasound can be oriented by directional transducers to destroy tissue selectively ${ }^{13}$. Thirdly, the therapeutic ultrasound transducer can be also used for imaging the treated area ${ }^{14}$. And finally, these particularly light applicators are of special value in treating mobile organs. Treating mobile organs by extra-corporeal surgery may require sophisticated methods for instrument guidance ${ }^{15}$, whereas the miniature applicator can simply be attached to the target organ to follow its movements.

The purpose of this article is to review the recently published literature on interstitial ultrasound applicators. It is presented in three sections: the technical aspects common to all applicators are first described. Then the different potential techniques for monitoring treatment administered by the interstitial route will be presented and illustrated through a review of image-guided interstitial thermal ablation. The third section will deal in detail with diverse medical applications.

\section{General description of interstitial applicators}

The ultrasound source of miniaturized applicators can be placed in direct contact with the target tissue. Unlike the extra-corporeal approach, there are no intermediary tissues that require preservation so it is possible to work with frequencies above $3 \mathrm{MHz}$, increasing the 
heat and inducing coagulation necroses without geometric focusing of the beam. An interstitial approach is thus very safe because the exponential decrease with distance of the deposited energy results in heating only around the transducer. This may be a disadvantage in certain applications, such as treating liver tumors which may be several centimeters in diameter. Lowering the frequency and compensating for the reduced absorption by significantly increasing the intensity deepens the thermal lesion ${ }^{16}$. By adding front layers to the transducer, Chopra et al. ${ }^{17}$ developed multi-frequency applicators with a view to modifying heating patterns during shots. More recently, Makin et al. ${ }^{14}$, using ultrasound applicators functioning at a frequency of $3.1 \mathrm{MHz}$, obtained thermal lesions in liver tumors in vivo that were compatible with those required for cancer treatment. The frequencies of interstitial applicators in the literature are usually within the $3-11 \mathrm{MHz}$ range. Nau et al. ${ }^{18}$ proposed multiple directional applicators, used simultaneously, for treating canine prostate cancer. In order to increase thermal lesion depth, Lafon et al. ${ }^{19}$ envisaged using slightly focused transducers to compensate for the attenuation-related pressure fall-off by increasing pressure in depth by focusing. This was effective, but the gain in depth was counter-balanced by the coagulation necrosis along the applicator. Ross et al. ${ }^{20}$ used a similar approach with curvilinear transducers and observed better ultrasound penetration. Melodelima et al. ${ }^{21}$ proposed increasing heat at some distance from the plane transducer by increasing local and distal attenuation through initiation of cavitation bubbles. Attenuation was increased only in the area where cavitation bubbles were present, making it possible to increase the density of absorbed power. The lesions induced ex vivo with cavitation bubbles were twice as deep as those without cavitation bubbles.

Despite the high frequency of the transducers, it may take several minutes to cause coagulation necroses because of the lack of focusing. Most applicators described in the literature use a transducer cooling-circuit: either on the front surface $e^{14,16,17,22,23}$, on the rear 
surface $^{13}$ or on both ${ }^{24}$. Where a cooling fluid circulates along the emitting surface of the transducer, it serves as a coupling medium between the transducer and the target area. Treatment transducers must have a light backing to optimize their electro-acoustic effect. Therefore, if the rear surface is cooled, air is used but water-cooling has been shown to work as well ${ }^{13}$. Melodelima et al. ${ }^{24}$ used an applicator with a rigid damper behind the transducer. Depending on the type of cooling system, tissue destruction was induced either on contact with the transducer, or just behind the cooling system. Nau et al. ${ }^{23}$ compared an applicator directly coupled to tissue with a cooled applicator within a catheter. Cooling enabled the hottest point in the tissue to be further away from the transducer thus increasing the depth of thermal lesions and improving the directivity of heating. It was necessary to turn off the cooling before the end of the shot so as to treat the superficial layers in contact with the cooling circuit. Cooling may also preserve the wall of any canal into which the applicator is introduced.

Nearly all the interstitial applicators described in the literature are side-view applicators, but for their research Gentry et al. ${ }^{25}$ preferred a front-view applicator (Figure 1a). Side-view applicators maximize the surface of the transducer and consequently treatment volume. Meininger et al. $^{22}$ produced a front-view applicator from a cylindrical transducer radiating latteraly, imbricated in two inflatable balloons (Figure 1d). A mixture of sterile water and a contrast agent circulating inside the inner balloon ensured coupling of the transducer towards the target. The outer balloon, filled with carbon dioxide, reflected the ultrasound wave towards the tip of the applicator. Many interstitial applicators have cylindrical transducers ${ }^{26-28}$ (Figure 1b). They have two main advantages: the full contour of the applicator is treated simultaneously and they are relatively simple to assemble. The transducer can be cut off at certain angles to facilitate treatment directivity ${ }^{23}$. It has been shown, however, that under identical exposure conditions, a plane transducer produces deeper thermal lesions than a 
cylindrical transducer. Lafon et al. $^{29}$ used a plane transducer to produce a cylindrical coagulation necrosis. Despite stepwise rotation of the applicator round its axis and the twenty elementary lesions required, an $8 \mathrm{~mm}$ deep cylindrical lesion was obtained more rapidly than with a cylindrical transducer. Melodelima et al. ${ }^{24}$ designed a cylindrical ultrasound phased array (Figure 1c). Reconstruction of a plane wave, using a phased array, generated a significantly larger lesion than that obtained from a cylindrical wave. Many applicators using mono or multi-element plane transducers for lateral applications have been developed ${ }^{16,30-34}$. Makin et al. ${ }^{14}$ made a plane phased array for side-view applicators. These applicators have to be rotated to treat the periphery. Rotation may be stepwise and mechanical ${ }^{35}$, stepwise and electronic $^{36}$ or continuous and mechanical ${ }^{14}$. As well as increasing treatment depth, directional transducers make it possible to obtain sectorial thermal lesions ${ }^{37}$. However, it should be borne in mind that remote transfer of rotation to the active part may complicate significantly applicator design. For example, endoscopic applicators require flexible shaft ${ }^{35}$. Heat deposition is limited to the size of the transducer, which is why longitudinal control of lesions requires multiple transducers ${ }^{32,38,39}$ or mechanical displacement of the applicator along its $\operatorname{axis}^{40}$. Jarosz ${ }^{41}$ proposed another design for side-view ultrasonic interstitial applicator. His waveguide applicator consisted of a G18 hypodermic needle attached via a conical velocity transformer to an extracorporeal piezoelectric disk operated at $1.0 \mathrm{MHz}$.

Another factor, common to interstitial applicators but not relevant to extra-corporeal applicators is the critical issue of sterilization. The interstitial approach very often involves direct contact with blood so sterilization must be very good. It is possible, however, to produce disposable interstitial applicators, since they are fairly simple and inexpensive. 


\section{Interstitial ultrasound treatment guidance}

In the literature most methods described for guiding interstitial ultrasound ablation are the same as those used for extra-corporeal treatment, particularly temperature MRI and ultrasound imaging which are used extensively. However, the interstitial approach requires specific developments which will be detailed below. As well as standard imaging techniques, fluoroscopy is of particular interest for positioning miniature endoscopic devices.

\section{MRI-guidance and monitoring of interstitial ultrasound applicators}

Magnetic resonance imaging (MRI) is an excellent non-invasive tool for guiding ultrasound treatments. In addition to the three dimensional visualization of the target region, MRI can provide quantitative fast thermometry based on the proton resonance frequency (PRF) method and allows online, automatic control of temperature evolution ${ }^{42}$ (Figure 2a). PRFS-based thermometry at mid-field to high field intensity (1.5 to $3.0 \mathrm{~T})$ currently provides temperature accuracy better then $1^{\circ} \mathrm{C}$ with a spatial resolution on the order of $1 \mathrm{~mm}$ and temporal

resolution on the order of $1 \mathrm{sec}$ for one plane of typically several centimetres ${ }^{43}\left(6 \times 6 \mathrm{~cm}^{2}\right)$. MRI also identifies necrotic zones with a good soft tissue contrast resolution and can be used to evaluate the therapeutic effect, mainly by injecting a bolus of gadopentetate dimeglumine and by using Gd-enhanced ${ }^{44,}$, , respiratory-gated T1-weighted sequence for the lesion assessment.

However, one fundamental problem in vivo for cancer treatment is to monitor the thermal effect with MRI and to account for the movement (respiratory and cardiac) which generates motion artefacts affecting the effectiveness of the treatment. Therefore, it has been shown ${ }^{44}$ that MR data acquisition may be synchronised to the ECG (i.e. cardiac gating) or breathing, at 
the cost of lower temporal resolution to reduce these artefacts. Suppression of flow artefacts from large vessels in the vicinity of the tumour also improved the stability of PRF thermometry.

To date, pre-clinical studies of MRI-guided interstitial ultrasound therapy have been reported for prostate, brain and oesophagus. Feasibility of the selective prostate thermal therapy with MRI-guided high intensity contact ultrasound (HICU) in continuous sonication mode was recently reported by Ross et al. ${ }^{20}$. An experimental study was performed in vivo in the canine prostate using a curvilinear transurethral applicator and demonstrating the interest of minimally invasive therapies for treating benign prostatic hyperplasia (BPH) or localized prostate cancer. Stepwise rotation of the beam at $10^{\circ}$ discrete angles were performed without any delay between sonications. A piezoelectric motor was used to perform the mechanical rotation under computer control. The ultrasound beam was rotated when MR thermometry indicated that a $52^{\circ} \mathrm{C}$ threshold temperature was reached at the prostate capsule. Therefore a controllable ablation was achieved in the prostate since the end point of an elementary sonication (for a given location) was automatically decided online by MR thermometry. A treatment angle of $180^{\circ}$ was achieved in 12 minutes in vivo, the sonication time at each position ranged from 41 to $127 \mathrm{sec}$ according to the thermal build up. The final thermal dose conformed to the predefined targeted region which can involved irregular prostate boundary. These results demonstrate that combining temperature imaging guidance with curvilinear applicator sweeping can result in fast volumetric prostate ablation, with relatively arbitrary outer boundaries of thermal necrosis. The temporal resolution of the MR thermometry was considered as the main limiting factor for improving the speed of the treatment.

Chopra et al. ${ }^{46}$ demonstrated, through theoretical simulations, the potential of clinical 1.5T scanner for performing MRI-thermometry in order to monitor transurethral thermal therapy with planar transducers. After developing a program that can adjust online exposure 
conditions (frequency, rotation and power) from the measured temperatures and acquiring images of prostate of potential patients, the principle of the technique was validated experimentally in a tissue mimicking phantom ${ }^{47}$.

Kangasniemi et al. ${ }^{48}$ reported the feasibility of multiplanar MR thermometry for measuring necrosing thermal doses during intracerebral thermal delivery by interstitial ultrasound applicators. Experiments were performed on dogs which received in the brain fragments of transmissible venereal tumours. The applicator was positioned in the brain and temperature was acquired and updated for five to seven planes during treatment every 6-8 seconds. Thermal doses were calculated from temperatures in order to estimate the coagulated volume. This volume was consistent with post treatment MRI and histology.

MR-guidance and thermal mapping for ultrasound intraluminal oesophageal ablation was demonstrated in vitro ${ }^{43}$ then in vivo ${ }^{44}$ with a single element flat transducer. Experiments were performed in vivo in pigs esophagi. Due to the location of the target, MR thermometry was respiratory and cardiac gated for an accuracy of temperature of $+/-1.5$ degrees $\mathrm{C}$ in the lower part of the oesophagus (under respiratory gating) and $+/-3.1$ degrees $\mathrm{C}$ for the upper part of oesophagus (under cardiac gating). Thermal lesions observed the sacrifice of the animal were very consistent with estimates from $\mathrm{Gd}$-enhanced $\mathrm{T}_{1}$-weighted images.

Recently, the principle of plane wave reconstruction and electronic rotation of the beam was demonstrated under MR-guidance in vitro using a cylindrical 1D phased array of 64 transducers $^{36}$. The described device is dedicated to sectorial ablation of oesophageal wall tumours. As electronic selection of the active elements avoids mechanical rotation of the device, motion-related artefacts in PRF-based MR thermometry were minimized and the targeting accuracy was improved significantly.

\section{Ultrasound guidance and monitoring of interstitial ultrasound applicators}


Ultrasound imaging is a less expensive technology as compared to MRI and is more widely available in operating rooms. No compatibility issues have to be taken into account. It has the advantage to be motion-robust and to provide high temporal and spatial resolution. In addition, as the same physical agent is used for imaging and for therapy, if propagation problems occur in the beam pathway (interfaces, scattering etc), it is possible in principle to predict and compensate them before the therapeutic sequence ${ }^{49}$. Low tissue contrast, poor visualisation of the tumour margins, 2D imaging and lack of immediate assessment of the therapeutic result are the main weaknesses of this approach. Temperature monitoring with ultrasound imaging has been demonstrated in vitro ${ }^{50}$ but problems subsists when temperature overwhelms $55^{\circ} \mathrm{C}$ and the method is extremely sensitive to motion in vivo. RF lines were processed in order to monitor thermal lesions: elastography ${ }^{51}$ ultrasound temperature monitoring $^{52}$ or echo-strain imaging ${ }^{53}$ but none of these methods were combined with interstitial thermal ablations.

Interstitial applicator placement can be usually guided by external B-scan ultrasound imaging $^{34}$ (except for particular locations like oesophagus or brain). With external ultrasound imaging the treatment monitoring capability is limited as external ultrasound is strongly scattered and attenuated by bubbles formed throughout the region of thermal ablation.

Ideally, the imaging device should therefore operate in situ, inside the ablation volume. Integration of separate imaging array and therapy transducers was the first available technology to perform this functionality. The main difficulty when using this approach is to build miniaturized devices compatible with minimally-invasive interstitial therapy. Given the restricted volume, possible geometrical interferences (ie B-mode beam reflection) because of the therapeutic transducer should be considered as a potential source of image artefacts. 
The interest of the integrated imaging - ablation catheter has been demonstrated for 3D intracardiac applications. Gentry et al. ${ }^{54}$ built a forward-looking device with a 112 element 2D imaging array $(5.4 \mathrm{MHz})$ and a separate ablation transducer. The last one consisted of a single element, annular, concentric focused transducer operating at $10 \mathrm{MHz}$. While encouraging results have been obtained ex vivo, one main limitation for the routine use in clinic of this device was considered to be the size of the tip (14 Fr).

A very elegant solution for in situ ultrasound guidance of the ablation consist of building dual-functionality arrays where the same transducer is used both for imaging and ablation (shared time imaging/ablation sequence based on rapid electronic switching between imaging and ablation modules). Imaged and treated volumes are then inherently co-registered (a single reference system is used), which simplifies the image-based targeting of the tumour. In addition, further miniaturization of devices becomes possible. Image quality is still challenging, first because of the geometrical limitations (limited probe dimension and channel count) and second because a compromise must be obtained between the acoustic efficiency and the pulse echo bandwidth. The imaging component should allow delineating boundaries between normal and abnormal tissue, to achieve spatial and contrast resolution sufficient to identify critical structures in the vicinity of the target volume and to enable monitoring of the ablation process during treatment.

According to Makin et al. ${ }^{14}$, interstitial ultrasound ablation using image-treat arrays is a viable method for bulk ablation of liver tissue in vivo. In this study a 32-element arrays with aperture $2.3 \times 49 \mathrm{~mm}$ has been used for rotationally scanned exposures in porcine liver. The array imaging module provided imaging capabilities similar to current clinical imaging systems, including B-mode, M-mode and colour Doppler imaging. The image quality achieved with these dual-mode arrays was reported comparable to imaging from standard 
trans-abdominal ultrasound imaging probes and is able to detect thermal lesioning (showed as a hyperechoic region after ultrasound as exposure).

\section{Fluoroscopic guidance of interstitial ultrasound applicators}

Another imaging modality suggested for guidance of interstitial ultrasound is the X-ray fluoroscopy. This technique has the advantage of providing real time, high spatial resolution and excellent contrast of the interventional device with respect to the anatomical background image. Specific constraints are related to the ionizing radiation which is used, while only a 2D projection of the imaged volume is available. Prat et al. ${ }^{40}$ reported the feasibility of endoscopic treatment of cholangiocarcinoma and carcinoma of the duodenal papilla by intraductal high-intensity ultrasound. The position of the stricture and relative placement of the ultrasonic probe was done under fluoroscopy after injection of contrast agents in the bile duct (Figure 2b). A pilot clinical study was performed on ten patients with promising palliative results.

Fluoroscopic guidance for focused ultrasound ring ablation outside the pulmonary vein for treatment of atrial fibrillation was reported by Meininger et al. ${ }^{22}$. Two perpendicular fluoroscopic views were used to assess the alignment of the focused ultrasound balloon ablation device engaged in the right superior pulmonary vein. A venogram was performed by contrast injection via the lumen of the ablation catheter with the balloon inflated, to allow visualization of the pulmonary vein architecture. This study showed that successful alignment of the ultrasound transducer and balloon within the pulmonary vein is feasible, allowing circumferential ablation lesions to be created isolating the pulmonary vein.

\section{Specific description of interstitial applicators of the literature}


Unlike extra-corporeal ultrasound applicators, the emitters of interstitial applicators are placed as close as possible to the target area, which involves using different ultrasound transducers from those of focused applicators. Furthermore, the geometry selected must take into account the shape of the region of interest. For these reasons, several transducer shapes have been suggested: cylindrical, semi-cylindrical, cylindrical with focusing by wave reflection, plane and cylindrical array. The miniaturization of interstitial applicators leads to further constraints on design and manufacture, depending on the access route to the target organ. There are flexible applicators for when the access route has bifurcations, and rigid applicators for a linear approach. As with focused extra-corporeal transducers, interstitial applicator design must meet the constraints imposed by the guidance methods. Either an ultrasound imaging cell must be integrated ${ }^{55}$, or the materials used must be compatible with an MR imaging environment $^{56,46,44}$.

\section{Ultrasound emitter geometry}

\section{Cylindrical transducers}

Some applicators have cylindrical or semi-cylindrical transducers. These applicators are usually small (1.5 to $2.5 \mathrm{~mm}$ in diameter) to facilitate insertion into a catheter ${ }^{56}$ or placement in direct contact with tissue ${ }^{23}$. At present, this technique is proposed for treatment of benign prostate hypertrophy $(\mathrm{BPH}){ }^{20}$ and prostate cancer ${ }^{56-58}$; to correct some forms of cardiac $\operatorname{arrhythmia}^{27}$ and for spinal treatments ${ }^{59}$. In general, the acoustic power of these applicators consists in several acoustic watts and treatment time lasts 15 to 20 minutes to reach temperatures of about $55^{\circ} \mathrm{C}$ in exposed tissue. The rapid depth-related pressure fall-off, induced by the divergent ultrasound source, limits treatment depth, and heat is deposited close to the transducer at a depth of about 10 to $20 \mathrm{~mm}$. It takes several minutes to make a deep 
thermal lesion and the temperature rises quickly in the shallowest layers. It is essential to prevent vaporization which creates an opaque barrier to ultrasound and hinders the treatment of deeper layers. Similarly, where applicators are placed in catheters, the catheter walls induce pressure fall-off, hindering ultrasound penetration and preventing heat from being deposited at depth. Moreover, the required exposure times mean that treatment efficacy depends on blood perfusion and the effect of heat diffusion. To resolve these problems and to facilitate deep treatments, the studies performed by Deardoff et al. ${ }^{28}$ used applicators directly in contact with tissues. An internal cooling system (water or air) removed the heat accumulating at the surface of the transducer and increased the power without reducing the applicator's performance and giving wider radial depths in the treated areas. In this way, thermal penetration was increased and treatment time reduced. It is necessary to have more implants (or re-implants) for treating larger volumes (diameters above $40 \mathrm{~mm}$ ) or for highly-perfused areas.

Because of the geometry of these transducers, the coagulated volumes are cylindrical, making it difficult to treat areas of sectorial tissues. Diederich et al. ${ }^{60}$ therefore proposed dividing the emitting part of the device into longitudinal sectors to control the angle opening (i.e. $40^{\circ}, 90^{\circ}$, $180^{\circ}$ or $270^{\circ}$ ) at which tissues are heated. Angle resolution is then limited to each applicator which is specially designed for a given angle opening. Some authors have also proposed using two or three transducers (sectorial or not) placed along an axis to obtain dynamic axial control of heat deposit ${ }^{61,56}$. It would then be possible to adjust the shape and axial dimensions of coagulation necroses by modulating the power emitted by each transducer. Kinsey et $\mathrm{al}^{38}$ have suggested multisector angular control without applicator movement, and not limited to a preset directional heating pattern. In addition, the power to multiple sectors can be controlled. As with cylindrical applicators, an internal cooling system would help control the angle at which heat is deposited by removing the energy accumulated on the transducer's internal 
surface $^{28}$. Similarly, the cooling system makes it possible to make a lesion of approximately the same length as the transducer in the axial direction ${ }^{13,60}$.

\section{Plane transducers}

Plane sources are usually rectangular ${ }^{16,31}$. Ultrasound penetrates deeply in the tissues compared with cylindrical emitters ${ }^{29}$ and are very precise, with narrow angular placement inducing necroses resembling rectangular parallelepipeds whose section is equal to the surface of the transducer and whose depth is adjustable, depending on the acoustic intensity and exposure time ${ }^{37}$. Each elementary necrosis is induced in approximately 20s. Acoustic intensity delivered by these applicators is approximately $20 \mathrm{~W} / \mathrm{cm}^{2}$ and tissues can be heated up to $80^{\circ} \mathrm{C}$. The treatment of a sector, or a cylinder, involves rotating the applicator on its axis after each ultrasound exposure. The treatment depth can reach a radius of $15 \mathrm{~mm}$. Treatment time for a cylindrical volume is similar to that with a cylindrical transducer (15 to 20 minutes). The main problem with plane transducers is the mechanical rotation which is sometimes difficult to perform in vivo. Rotating the plane waves makes it possible to treat tissues lying at angles and to modulate the depth of necrosis according to the treatment angle. To make an elementary necrosis, sonification time is about 10 seconds, which means that treatment is not affected by blood perfusion ${ }^{62}$. The shape of necroses can thus be carefully controlled. These applicators were used clinically to destroy tumors of the biliary and esophageal tracts ${ }^{31,40}$.

Gentry et al. ${ }^{54}$ suggested another use for plane transducers: an annular transducer with a 14 $\mathrm{mm}$ outer diameter and a $2.5 \mathrm{~mm}$ inner diameter (Figure 1a). A matrix of ultrasound transducers is placed in the center of the annular ultrasound emitter to image the treatment area. The positioning of the treatment and imaging transducers at the distal tip of the 
applicator makes it possible to apply treatment on the axis of the applicator. This is not possible with the techniques described for lateral shots.

\section{Multi-element cylindrical transducers}

If the active part of the device is composed of several transducers (Figure 1b), the shape and the intensity of the created pressure field can be electronically controlled by modulating the amplitude and the phase applied to each element. The site of heat deposition may then be displaced without mechanical movements. Several designs have been suggested ${ }^{32,63,14}$ and treatment times are greatly reduced if phased arrays are used ${ }^{64,65}$. Therefore, to resolve the problems posed by treating esophageal tumours, Melodelima et al. ${ }^{36}$ tried using a $10 \mathrm{~mm}$ diameter cylindrical ultrasound applicator composed of 64 elementary transducers functioning at $4.55 \mathrm{MHz}$, and spread around the periphery of the cylinder (Figure 1c). With this configuration, the ultrasound field was naturally divergent. To render propagation planar, eight consecutive elements were excited with appropriate delay times ${ }^{24}$. In this case, the mechanical movement of the applicator is replaced by electronic rotation of the ultrasound beam using eight other elements to change shot direction. This method guarantees more accurate shot angles and sonication sequences that are not dependent on mechanical constraints with improved suitability for MR guided applications.

\section{Focused transducers}

Applicators (Transurgical Inc., Setauket, NY) are used in clinic to treat atrial fibrillation. The applicator is placed in the pulmonary vein for ring ablation outside the vein ${ }^{22}$. The applicator comprises a flexible tube ( 8 Fr) containing several channels. A 0.035 -in wire guide passes through the central channel and two other channels access the balloons (inner and outer) surrounding a cylindrical ultrasound transducer (Figure 1d). The inner balloon, surrounding 
the transducer, contains sterile water for cooling and a contrast agent to visualize the probe and help position it in the treatment area. The outer balloon contains carbon dioxide to create a liquid-gas interface for rupturing acoustic impedance with consequent reflection of the ultrasound wave. The parabolic shape of the inner balloon focuses the ultrasound energy in a ring and creates circumferential ablation. Each ultrasound exposure creates a circumferential necrosis $(6 \mathrm{~mm}$ in height by $2 \mathrm{~cm}$ in diameter) at some distance from the emitter, unlike other non-focused interstitial techniques.

\section{Applicator bodies}

One advantage of interstitial applicators is that the desirable transducer platform can be integrated into either a "flexible" or "rigid" device according to the location of the tumour to be treated. In the literature, flexible applicators were used mainly in the GI tract, especially for treatment of biliary and oesophageal tumors ${ }^{31,37}$, and more recently by vascular routes for treating atrial fibrillation ${ }^{66}$. Biliary duct cancers were treated using an applicator $(4 \mathrm{~mm}$ in diameter and $2 \mathrm{~m} \mathrm{long}$ ) inserted into a video-duodenoscope. Access is by the mouth, down the oesophagus, through the stomach and duodenum and into the biliary tract. The endoscope is placed in the duodenum; the tip of the applicator fitted with the ultrasound transducer slides on a guidewire outside the endoscope and enters the biliary duct until in contact with the tumour. Figure $2 \mathrm{~b}$ demonstrates the flexibility of an applicator used to treat biliary duct cholangio-carcinoma. The treatment method, using a plane transducer, consists in rotating the applicator round its axis to obtain a cylindrical coagulation necrosis conforming to the tumour shape. Therefore, as well as being flexible, the applicator must accurately transmit a rotation movement over a distance of two meters. The rotation is transmitted using a flexible spring (3.8 $\mathrm{mm}$ diameter). A similar method using a shorter $(90 \mathrm{~cm}$ long) wider $(10 \mathrm{~mm})$ probe is 
used for oesophageal tumors ${ }^{40}$. Depending on the number of ultrasound exposures delivered by the plane transducer, the treatment angle can be adjusted to a sectorial tumor ${ }^{37}$.

To treat atrial fibrillation, Meininger et al. ${ }^{22}$ used a catheter containing a flexible applicator. At its tip there was a cylindrical transducer surrounded by a water-filled balloon. The treatment consists in passing the catheter containing the ultrasound transducer, fitted to a guide wire, into a pulmonary vein through an 8 Fr catheter (Naviport, Cardina Inc., Fremont, CA). The balloon surrounding the transducer is then inflated with $5.6 \mathrm{cc}$ of sterile water. The outer balloon, for focusing the ultrasound waves on a ring, is then inflated with $1.4 \mathrm{cc}$ of carbon dioxide.

Applicators with rigid bodies are used when the pathway between the ultrasound emitter and the treatment area is short and linear. This technology is easier and cheaper to make. For these

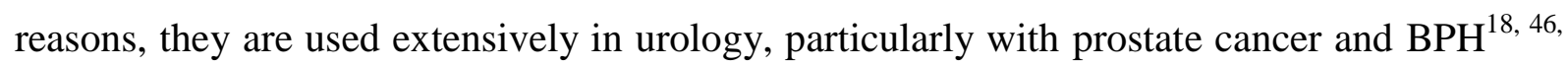
${ }^{67}$ although applications for hepatology ${ }^{14}$ and spinal therapy ${ }^{59}$ have been proposed recently. The applicators used for BPH and spinal therapy have rigid probes, a few millimetres in diameter $(1.5$ to $6 \mathrm{~mm})$ and a few centimetres long, so they can be placed either inside a trochar, or catheter, to guide the probe to the target area, or used percutaneously, particularly when treating the liver and spine.

\section{Conclusions}

This review shows the diversity of interstitial applicators for ablating thermally tissues by high intensity ultrasound. These applicators aim to treat digestive diseases (in the bile duct, the oesophagus or liver), prostatic or cerebral tumours and atrial fibrillation.

Very rapid progresses were done in the field of interstitial ultrasound applicators for thermal ablation within the last 15 years. Since the first tests for hyperthermic applications in 
conjunction with brachytherapy, the technology of the transducers improved. New piezo electric material enables generating enough power for performing thermal ablation with these miniature transducers. More sophisticated applicators were developed based on multielements transducers and a technological jump was done with the possibility of combining interstitial arrays imaging and therapeutic capabilities. In parallel, significant developments were done in monitoring and guidance of the interstitial ultrasound treatments. Only a few clinical trials were performed following an interstitial approach however these rapid and recent developments tend to prove that much more will be done in a near future. The simplicity of the applicators will favour the spread of the technique in the hospitals. As many modalities are used for treating interstitially tissues, the field is extremely competitive but ultrasound technologies present major advantages (one of them is the dual mode capability) that should help them to overwhelm and replace concurrent modalities.

In the same manner as extracorporeal, endocavitary and intraluminal imaging probes coexist, interstitial and extracorporeal applications of high intensity ultrasound are complementary. Depending on the situation, one of the two options (extracorporeal or interstitial) may be preferable. In situations where both approaches could be used, a choice must be done between the relative invasiveness of interstitial applicators and the generation of focused beams on hard-to-reach and/or mobile targets.

However, guiding techniques are common to extracorporeal and interstitial applications of high intensity ultrasound. Only fluoroscopy commonly used during endoscopic procedures is specific to interstitial ultrasound. Although most transducers used as interstitial sources are not focused, the expression "HIFU" is still relevant to these applications. Just like "conventional" HIFU, the treatment by high intensity ultrasound with interstitial probes is focused. Recent technological advances lead to developments of dual mode interstitial probes able to perform both imaging and therapy. Future innovations can easily be foreseen with the 
miniaturization of electronics and transducers. We can imagine MR-compatible probes with integrated antenna for improved image quality. These interstitial probes could also probably be used in the emerging field of drug delivery. The close proximity of the target to the applicator could enable directly injection or delivery of drugs to the target volume of tissue. 


\section{References}

1. Fry WJ, Mosberg WH, Jr., Barnard JW, Fry FJ. Production of focal destructive lesions in the central nervous system with ultrasound. J Neurosurg 1954;11(5):471-8.

2. Gelet A, Chapelon JY, Bouvier R, et al. Transrectal high intensity focused ultrasound for the treatment of localized prostate cancer: factors influencing the outcome. Eur Urol 2001;40(2):124-9.

3. Uchida T, Sanghvi NT, Gardner TA, et al. Transrectal high-intensity focused ultrasound for treatment of patients with stage $\mathrm{T} 1 \mathrm{~b}-2 \mathrm{n} 0 \mathrm{~m} 0$ localized prostate cancer: a preliminary report. Urology 2002;59(3):394-8; discussion 398-9.

4. Tempany CM, Stewart EA, McDannold N, et al. MR imaging-guided focused ultrasound surgery of uterine leiomyomas: a feasibility study. Radiology 2003;226(3):897-905.

5. Wu F, Wang ZB, Chen WZ, et al. Extracorporeal high intensity focused ultrasound ablation in the treatment of 1038 patients with solid carcinomas in China: an overview. Ultrason Sonochem 2004;11(3-4):149-54.

6. Illing RO, Kennedy JE, Wu F, et al. The safety and feasibility of extracorporeal highintensity focused ultrasound (HIFU) for the treatment of liver and kidney tumours in a Western population. Br J Cancer 2005;93(8):890-5.

7. Hynynen K. The feasibility of interstitial ultrasound hyperthermia. Med Phys 1992;19(4):979-87.

8. Tateishi R, Shiina S, Teratani T, et al. Percutaneous radiofrequency ablation for hepatocellular carcinoma. An analysis of 1000 cases. Cancer 2005;103(6):1201-9.

9. Vogl TJ, Straub R, Zangos S, et al. MR-guided laser-induced thermotherapy (LITT) of liver tumours: experimental and clinical data. Int J Hyperthermia 2004;20(7):713-24.

10. Rivoire M, De Cian F, Meeus P, et al. Combination of neoadjuvant chemotherapy with cryotherapy and surgical resection for the treatment of unresectable liver metastases from colorectal carcinoma. Cancer 2002;95(11):2283-92.

11. Seegenschmiedt MH, Feldmann HJ, Wust P, Molls M. Hyperthermia--its actual role in radiation oncology. Part IV: Thermo-radiotherapy for malignant brain tumors. Strahlenther Onkol 1995;171(10):560-72.

12. Deardorff DL, Diederich CJ, Nau WH. Control of interstitial thermal coagulation: comparative evaluation of microwave and ultrasound applicators. Med Phys 2001;28(1):104-17.

13. Deardorff DL, Diederich CJ. Axial control of thermal coagulation using a multielement intestitial ultrasound applicator with internal cooling. IEEE Trans. Ultrason. Ferroelec. Freq. Contr. 2000;47(1):1541-1545.

14. Makin IR, Mast TD, Faidi W, et al. Miniaturized ultrasound arrays for interstitial ablation and imaging. Ultrasound Med Biol 2005;31(11):1539-50.

15. Pernot M, Tanter M, Fink M. 3-D real-time motion correction in high-intensity focused ultrasound therapy. Ultrasound Med Biol 2004;30(9):1239-49.

16. Lafon C, Chapelon JY, Prat F, et al. Design and preliminary results of an ultrasound applicator for interstitial thermal coagulation. Ultrasound Med Biol 1998;24(1):11322.

17. Chopra R, Luginbuhl C, Foster FS, Bronskill MJ. Multifrequency ultrasound transducers for conformal interstitial thermal therapy. IEEE Trans Ultrason Ferroelectr Freq Control 2003;50(7):881-9. 
18. Nau WH, Diederich CJ, Ross AB, et al. MRI-guided interstitial ultrasound thermal therapy of the prostate: a feasibility study in the canine model. Med Phys 2005;32(3):733-43.

19. Lafon C, de L, Theillere Y, et al. Optimizing the shape of ultrasound transducers for interstitial thermal ablation. Med Phys 2002;29(3):290-7.

20. Ross AB, Diederich CJ, Nau WH, et al. Curvilinear transurethral ultrasound applicator for selective prostate thermal therapy. Med Phys 2005;32(6):1555-65.

21. Melodelima D, Cathignol D. Cancer treatment by ultrasound: increasing the depth of necrosis. Applied Physics Letters 2004;84(26):5365-5367.

22. Meininger GR, Calkins H, Lickfett L, et al. Initial experience with a novel focused ultrasound ablation system for ring ablation outside the pulmonary vein. J Interv Card Electrophysiol 2003;8(2):141-8.

23. Nau WH, Diederich CJ, Stauffer PR. Directional power deposition from directcoupled and catheter-cooled interstitial ultrasound applicators. Int J Hyperthermia 2000;16(2):129-44.

24. Melodelima D, Lafon C, Prat F, et al. Ultrasound cylindrical phased array for transoesophageal thermal therapy: initial studies. Phys Med Biol 2002;47(23):4191203.

25. Gentry KL, Sachedina N, Smith SW. Catheter ultrasound phased-array transducers for thermal ablation: a feasibility study. Ultrason Imaging 2005;27(2):89-100.

26. Diederich CJ, Hynynen K. The development of intracavitary ultrasonic applicators for hyperthermia: a design and experimental study. Med Phys 1990;17(4):626-34.

27. Hynynen K, Dennie J, Zimmer JE, et al. Cylindrical ultrasonic transducers for cardiac catheter ablation. IEEE Trans Biomed Eng 1997;44(2):144-51.

28. Deardorff DL, Diederich CJ, Nau WH. Air-cooling of direct-coupled ultrasound applicators for interstitial hyperthermia and thermal coagulation. Med Phys 1998;25(12):2400-9.

29. Lafon C, Chavrier F, Prat F, et al. Theoretical comparison of two interstitial ultrasound applicators designed to induce cylindrical zones of tissue ablation. Med Biol Eng Comput 1999;37(3):298-303.

30. Zimmer JE, Hynynen K, He DS, Marcus F. The feasibility of using ultrasound for cardiac ablation. IEEE Trans Biomed Eng 1995;42(9):891-7.

31. Prat F, Lafon C, Theilliere JY, et al. Destruction of a bile duct carcinoma by intraductal high intensity ultrasound during ERCP. Gastrointest Endosc 2001;53(7):797-800.

32. Chopra R, Bronskill MJ, Foster FS. Feasibility of linear arrays for interstitial ultrasound thermal therapy. Med Phys 2000;27(6):1281-6.

33. Pisani LJ, Ross AB, Diederich CJ, et al. Effects of spatial and temporal resolution for MR image-guided thermal ablation of prostate with transurethral ultrasound. J Magn Reson Imaging 2005;22(1):109-18.

34. Wong RF, Bhutani MS. Therapeutic endoscopy and endoscopic ultrasound for gastrointestinal malignancies. Expert Rev Anticancer Ther 2005;5(4):705-18.

35. Lafon C, Theillere Y, Prat F, et al. Development of an interstitial ultrasound applicator for endoscopic procedures: animal experimentation. Ultrasound Med Biol 2000;26(4):669-75.

36. Melodelima D, Salomir R, Mougenot C, et al. 64-Element intraluminal ultrasound cylindrical phased array applicator compatible with magnetic resonance imaging for transesophageal thermal ablation. Med Phys 2006;33(8):2926-2934. 
37. Melodelima D, Lafon C, Prat F, et al. Transoesophageal ultrasound applicator for sector-based thermal ablation: first in vivo experiments. Ultrasound Med Biol 2003;29(2):285-91.

38. Kinsey AM, Diederich CJ, Tyreus PD, et al. Multisectored interstitial ultrasound applicators for dynamic angular control of thermal therapy. Med Phys 2006;33(5):1352-63.

39. Nau WH, Diederich CJ, Burdette EC. Evaluation of multielement catheter-cooled interstitial ultrasound applicators for high-temperature thermal therapy. Med Phys 2001;28(7):1525-34.

40. Prat F, Lafon C, Melodelima D, et al. Using Intraductal ultrasound for the treatment of digestive tumours: First clinical results. Proceedings of the 3rd International Symposium on Therapeutic Ultrasound, Lyon, France 2003:145-150.

41. Jarosz BJ. Feasibility of ultrasound hyperthermia with waveguide interstitial applicator. IEEE Trans Biomed Eng 1996;43(11):1106-15.

42. Palussiere J, Salomir R, Le Bail B, et al. Feasibility of MR-guided focused ultrasound with real-time temperature mapping and continuous sonication for ablation of VX2 carcinoma in rabbit thigh. Magn Reson Med 2003;49(1):89-98.

43. Melodelima D, Salomir R, Mougenot C, et al. Intraluminal ultrasound applicator compatible with magnetic resonance imaging "real-time" temperature mapping for the treatment of oesophageal tumours: an ex vivo study. Med Phys 2004;31(2):236-44.

44. Melodelima D, Salomir R, Chapelon JY, et al. Intraluminal high intensity ultrasound treatment in the esophagus under fast MR temperature mapping: in vivo studies. Magn Reson Med 2005;54(4):975-82.

45. Hynynen K, Clement GT, McDannold N, et al. 500-element ultrasound phased array system for noninvasive focal surgery of the brain: a preliminary rabbit study with ex vivo human skulls. Magn Reson Med 2004;52(1):100-7.

46. Chopra R, Wachsmuth J, Burtnyk M, et al. Analysis of factors important for transurethral ultrasound prostate heating using MR temperature feedback. Phys Med Biol 2006;51(4):827-44.

47. Chopra R, Burtnyk M, Haider MA, Bronskill MJ. Method for MRI-guided conformal thermal therapy of prostate with planar transurethral ultrasound heating applicators. Phys Med Biol 2005;50(21):4957-75.

48. Kangasniemi M, Diederich CJ, Price RE, et al. Multiplanar MR temperature-sensitive imaging of cerebral thermal treatment using interstitial ultrasound applicators in a canine model. J Magn Reson Imaging 2002;16(5):522-31.

49. Montaldo G, Tanter M, Fink M. Real time inverse filter focusing through iterative time reversal. J Acoust Soc Am 2004;115(2):768-75.

50. Pernot M, Tanter M, Bercoff J, et al. Temperature estimation using ultrasonic spatial compound imaging. IEEE Trans Ultrason Ferroelectr Freq Control 2004;51(5):606-15.

51. Ophir J, Cespedes I, Ponnekanti H, et al. Elastography: a quantitative method for imaging the elasticity of biological tissues. Ultrason Imaging 1991;13(2):111-34.

52. Miller NR, Bograchev KM, Bamber JC. Ultrasonic temperature imaging for guiding focused ultrasound surgery: effect of angle between imaging beam and therapy beam. Ultrasound Med Biol 2005;31(3):401-13.

53. Souchon R, Bouchoux G, Maciejko E, et al. Monitoring the formation of thermal lesions with heat-induced echo-strain imaging: a feasibility study. Ultrasound Med Biol 2005;31(2):251-9.

54. Gentry KL, Palmeri ML, Sachedina N, Smith SW. Finite-element analysis of temperature rise and lesion formation from catheter ultrasound ablation transducers. IEEE Trans Ultrason Ferroelectr Freq Control 2005;52(10):1713-21. 
55. Poissonnier L, Chapelon JY, Rouviere O, et al. Control of Prostate Cancer by Transrectal HIFU in 227 Patients. Eur Urol 2006.

56. Diederich CJ, Nau WH, Ross AB, et al. Catheter-based ultrasound applicators for selective thermal ablation: progress towards MRI-guided applications in prostate. Int $\mathbf{J}$ Hyperthermia 2004;20(7):739-56.

57. Diederich CJ, Burdette EC. Transurethral ultrasound array for prostate thermal therapy: initial studies. . IEEE Trans Ultrason Ferroelectr Freq Control 1996;43(6):1011-22.

58. Diederich CJ, Nau WH, Burdette EC, et al. Combination of transurethral and interstitial ultrasound applicators for high-temperature prostate thermal therapy. Int $\mathbf{J}$ Hyperthermia 2000;16(5):385-403.

59. Nau WH, Diederich CJ, Shu R. Feasibility of using interstitial ultrasound for intradiscal thermal therapy: a study in human cadaver lumbar discs. Phys Med Biol 2005;50(12):2807-21.

60. Diederich CJ, Stafford RJ, Nau WH, et al. Transurethral ultrasound applicators with directional heating patterns for prostate thermal therapy: in vivo evaluation using magnetic resonance thermometry. Med Phys 2004;31(2):405-13.

61. Hynynen K, Davis KL. Small cylindrical ultrasound sources for induction of hyperthermia via body cavities or interstitial implants. Int $\mathbf{J}$ Hyperthermia 1993;9(2):263-74.

62. Billard BE, Hynynen K, Roener RB. Effects of physical parameters on high temperature ultrasound hyperthermia. Ultrasound Med Biol 1990;16:409-420.

63. Chopra R, Luginbuhl C, Weymouth AJ, et al. Interstitial ultrasound heating applicator for MR-guided thermal therapy. Phys Med Biol 2001;46(12):3133-45.

64. Fan X, Hynynen K. A study of various parameters of spherically curved phased arrays for noninvasive ultrasound surgery. Phys Med Biol 1996;41(4):591-608.

65. Goss SA, Frizell LA, Kouzmanoff JT, et al. Sparse random ultrasound phased arrays for ultrasound surgery. IEEE Trans. Ultrason. Ferroelec. Freq. Contr. 1996;43(6):1111-1121.

66. Natale A, Pisano E, Shewchik J, et al. First human experience with pulmonary vein isolation using a through-the-balloon circumferential ultrasound ablation system for recurrent atrial fibrillation. Circulation 2000;102(16):1879-82.

67. Lafon C, Koszek L, Chesnais S, et al. Feasibility of a transurethral ultrasound applicator for coagulation in prostate. Ultrasound Med Biol 2004;30(1):113-22. 


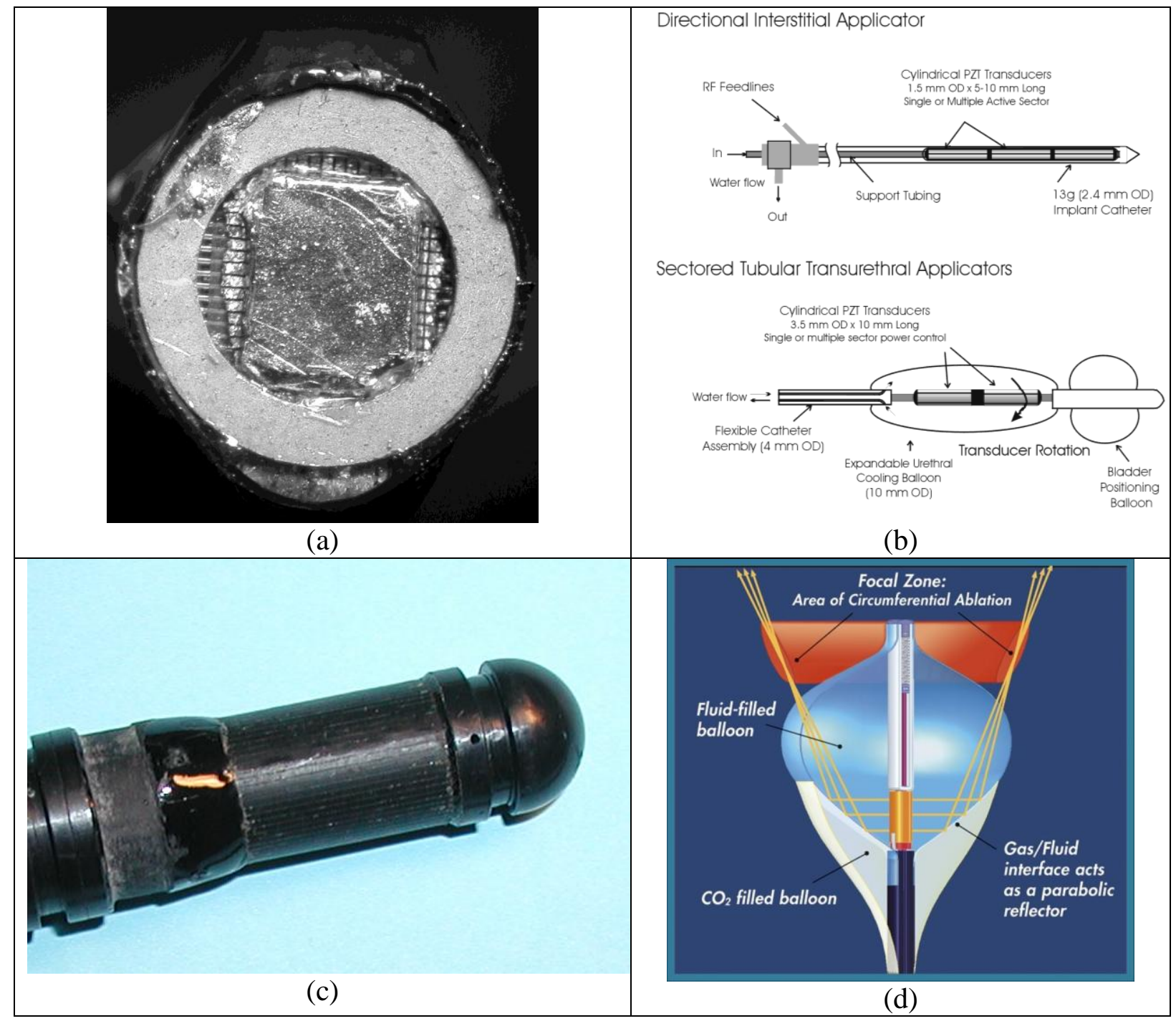

Figure 1. Transducers for interstitial applications: (a) Tip of a dual mode intracardiac ablation tool. The applicator consists in a 112-elements imaging array surround by a coagulating ring (Courtesy of KL Gentry). (b) Multi-element cylindrical transducers for coagulation in prostate under MR guidance (Courtesy of CJ Diederich and WH Nau). (c) 64-elements cylindrical array for treating esophageal tumours. Plane waves are reconstructed and rotated electronically. (d) Intracardiac catheter producing focused coagulation around the pulmonary vein for treating atrial fibrilation (Courtesy of DA Smith, ProRhythm, Inc.). 


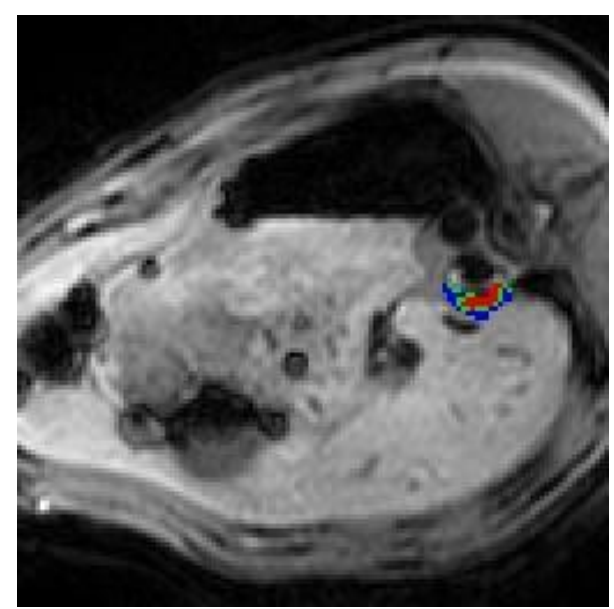

(a)

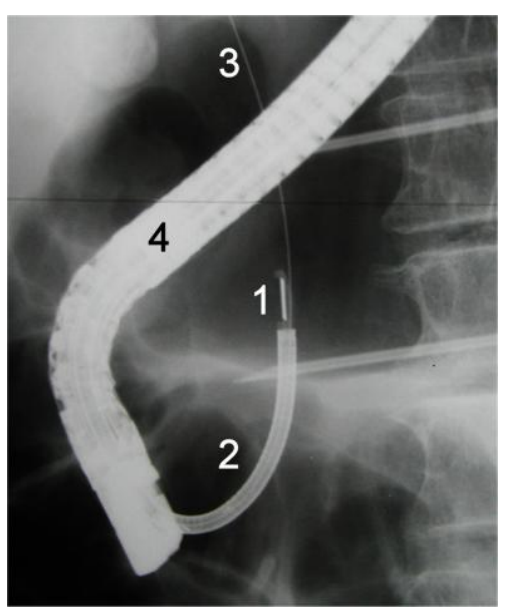

(b)

Figure 2. (a) Temperature map acquired in vivo during an ultrasound exposure using interstitial applicator. The applicator is positioned in the esophagus. The absolute temperature scale 42 to $47^{\circ} \mathrm{C}$ for the regions shown in blue, 48 to $52^{\circ} \mathrm{C}$ for regions in green, and above $53^{\circ} \mathrm{C}$ for regions in red. (b) Fluoroscopic image for positioning an endoscopic ultrasound applicator in the bile duct and treating cholangiocarcinoma. 1- Ultrasound therapeutic transducer, 2 - Applicator, 3 - Guide wire, 4 - Endoscope. 